\title{
Regulation of UGT1A1 and HNF1 transcription factor gene expression by DNA methylation in colon cancer cells
}

\author{
Anne-Sophie Bélanger ${ }^{1}$, Jelena Tojcic ${ }^{1}$, Mario Harvey ${ }^{1}$, Chantal Guillemette ${ }^{1,2^{*}}$
}

\begin{abstract}
Background: UDP-glucuronosyltransferase 1A1 (UGT1A1) is a pivotal enzyme involved in metabolism of SN-38, the active metabolite of irinotecan commonly used to treat metastatic colorectal cancer. We previously demonstrated aberrant methylation of specific CPG dinucleotides in UGT1A1-negative cells, and revealed that methylation state of the UGT1A1 5'-flanking sequence is negatively correlated with gene transcription. Interestingly, one of these CpG dinucleotides ( $C P G-4)$ is found close to a HNF1 response element (HRE), known to be involved in activation of UGT1A1 gene expression, and within an upstream stimulating factor (USF) binding site.

Results: Gel retardation assays revealed that methylation of CpG-4 directly affect the interaction of USF1/2 with its cognate sequence without altering the binding for HNF1-alpha. Luciferase assays sustained a role for USF1/2 and HNF1-alpha in UGT1A1 regulation in colon cancer cells. Based on the differential expression profiles of HNF1A gene in colon cell lines, we also assessed whether methylation affects its expression. In agreement with the presence of CpG islands in the HNFIA promoter, treatments of UGT1A1-negative HCT116 colon cancer cells with a DNA methyltransferase inhibitor restore HNF1A gene expression, as observed for UGT1A1.

Conclusions: This study reveals that basal UGT1A1 expression in colon cells is positively regulated by HNF1-alpha and USF, and negatively regulated by DNA methylation. Besides, DNA methylation of HNF1A could also play an important role in regulating additional cellular drug metabolism and transporter pathways. This process may contribute to determine local inactivation of drugs such as the anticancer agent SN-38 by glucuronidation and define tumoral response.
\end{abstract}

\section{Background}

Irinotecan (CPT-11) is a topoisomerase I inhibitor and one of the main cytotoxic agent for treatment of advanced metastatic colorectal cancer [1-3]. In vivo, irinotecan is converted to 7-ethyl-10-hydroxycamptothecin (SN-38), by a carboxylesterase-mediated hydrolysis, a metabolite $\sim 1000$-fold more active as topoisomerase I inhibitor than irinotecan $[4,5]$. The elimination pathway of the active metabolite $\mathrm{SN}-38$ is primarily through glucuronidation, which is mainly mediated by the UDPglucuronosyltransferase (UGT) 1A1 enzyme [6-8]. Low rates of $\mathrm{SN}-38$ glucuronidation in tumor sites increase the level of the active compound that could lead to higher sensitivity to irinotecan. In contrast, high levels

\footnotetext{
* Correspondence: chantal.guillemette@crchul.ulaval.ca

'Pharmacogenomics Laboratory, Centre Hospitalier Universitaire de Québec (CHUQ), 2705 Laurier, Quebec, G1V 4G2, Canada
}

of UGT activity and expression were associated with an increase of $\mathrm{SN}-38$ resistance in colon cancer cells [9]. Therefore, the regulation of UGT1A gene expression together with other mechanisms altering its protein activity should be considered in tumor resistance to SN-38.

Epigenetic regulation is a key mechanism to either activate or silence gene transcription, and abnormal epigenetic regulation has been described as an important characteristic of tumor malignancy and progression $[10,11]$. Furthermore, abnormal methylation of genes is a more common mechanism influencing gene activity than inheritable genetic mutations [12], and might confer intrinsic drug resistance to chemotherapeutic treatment. More specifically, colorectal cancer (CRC) is commonly associated with an abnormal methylation of $\mathrm{CpG}$ rich site (CpG island) in promoter region of

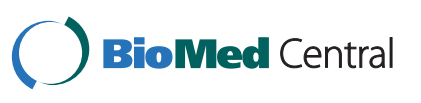

(c) 2010 Bélanger et al; licensee BioMed Central Ltd. This is an Open Access article distributed under the terms of the Creative Commons Attribution License (http://creativecommons.org/licenses/by/2.0), which permits unrestricted use, distribution, and reproduction in any medium, provided the original work is properly cited. 
multiple loci $[10,11]$. Indeed, a subset of CRC exhibit promoter methylation in multiple genes, referred to as the CpG island methylator phenotype $[10,13]$. Hence, it is rational to propose that abnormal epigenetic regulation of SN-38-metabolizing genes would be a drug resistance mechanism.

We previously demonstrated aberrant methylation of specific CpG-rich regions in UGT1A1-negative cells (HCT116, HCT-15, and COLO-320DM), and such events result in complete repression of UGT1A1 transcriptional activity [14]. DNA methylation may repress transcription by sterically hindering the binding of activating transcription factors (TFs) to their recognition sites [15-17]. Similarly, treatment with DNA methylation inhibitors enable binding of positive TFs and lead to gene reactivation [18]. In our previous report, treatment with demethylating and histone deacetylase inhibitor agents had the capacity to reverse aberrant hypermethylation and to restore UGT1A1 expression in hypermethylated UGT1A1-negative cells HCT116, but not in hypomethylated cells. Loss of UGT1A1 methylation was further associated with an increase in UGT1A1 protein levels and with an enhanced SN-38 inactivation, by $300 \%$ in HCT116 colon cancer cells [14]. In addition, human colon cancer cells has revealed that hypomethylation of the UGT1A1 5'-flanking sequence (-540 to -1$)$ is important for $U G T 1 A 1$ transcription. More specifically, the extent of UGT1A1 promoter methylation between CpG-1 (-4nt relative to the ATG) and -4 (-99nt relative to the ATG) of the promoter was shown to significantly predict $U G T 1 A 1$ gene expression in colon cancer cell lines [14]. It is proposed that DNA methylation would alter the binding affinity of some important positive TFs.

In this report, we identified $\mathrm{TF}(\mathrm{s})$ that bind and influence transcriptional activity of $U G T 1 A 1$ proximal promoter and determined whether methylation of $\mathrm{CpG}$ dinucleotides in this genomic region prevents binding of positive transcription factors.

\section{Results}

USF1/2 and HNF1-alpha bind the UGT1A1 gene promoter and activate transcription

By using a computer-based approach (MatInspector; http://www.genomatix.de/), several putative TF binding sites were observed in UGT1A1 5'-flanking sequence $(-540$ to -1$)$, namely NF-Y $(-57$ to -73$)$, HNF1-alpha (-79 to -95$)$, CDX2 (-98 to -118$)$, USF (-87 to -110$)$ and OCT1 (-274 to -293$)$ binding sites encompassing CpG-1 to -5 (Figure 1). Among those TFs, HNF1-alpha, CDX2 and OCT1 have previously been shown to interact with some UGT1A isoforms [19-25], but the interaction with UGT1A1 was only demonstrated for HNF1-alpha [26]. Interestingly, the CpG-4 is included in the USF recognition core sequence, the CpG-3 is part of the NF-Y/PBX binding site, and the HNF1 response element (HRE) is found between CpG-3 and -4 .

To address whether NF-Y, HNF1-alpha, CDX2, USF1/ 2 , and OCT1 might specifically bind to the proximal promoter of $U G T 1 A 1$, electrophoretic mobility shift assays (EMSA) were performed using nuclear protein extracts from HT29 cells, and synthetic double-stranded oligonucleotides derived from the UGT1A1 promoter sequence and containing each putative TF binding site (see Table 1). DNA-protein complexes are formed with all transcription factor-associated oligonucleotide probes, except for CDX2 and PBX (Figure 2). Each specific DNA-protein complex was competed by the addition of 100-fold molar excess of either the consensus recognition sequence or the unlabeled probe, thus providing evidence for specific binding. To further support the identity of DNA-binding proteins, we performed binding assays in presence of specific antibodies. The addition of mouse monoclonal anti-USF1 and anti-USF2 led to the formation of a supershifted DNA-protein complex (designated as $S$ in figure 2) with the USF response element (URE)-containing probe, likely indicating that both USF1 and USF2 might bind to UGT1A1 promoter. Similar results were observed with the specific anti-HNF1-alpha and NF-Y antibodies, whereas the presence of anti-OCT1 antibody did not affect the formation of DNA-protein complex III with the OCT1specific probe. The later likely indicates that an unknown DNA-binding protein might interact with this UGT1A1 promoter sequence.

To investigate the functional importance of these DNA-protein interactions, namely with USF1/2, HNF1alpha, NF-Y, and OCT1, upon UGT1A1 proximal promoter activity, we disrupted either of their predicted recognition sequences in a 540 bp fragment of the

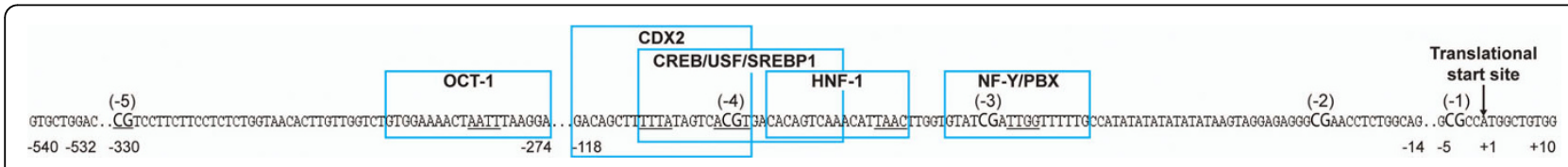

Figure 1 Putative transcription factor binding sites in human UGT1A1 proximal promoter. Schematic representation of the UGT1A1 gene sequence between positions -540 and +10 (relative to the transcription start site). Positions of CpG dinucleotides are shown. Sequences of the putative transcription factor binding sites are boxed. The recognition core sequence for each transcription factor is underlined. 


\begin{tabular}{llll}
\hline Transcient transfection experiement & & & \\
\hline Transcription factor $^{\text {a }}$ & & & \\
OCT1 & $5^{\prime}$ & GGTCTGTGGAAATACTGGCCTAATGGATCCTGAGGTTC & $3^{\prime}$ \\
CDX2 & $5^{\prime}$ & GTGGACTGACAGCTITCGCCGTCACGTGACACAGTC & $3^{\prime}$ \\
USF & $5^{\prime}$ & GCTITTATAGTCAATTGACACAGTCAAAC & $3^{\prime}$ \\
HNF1 & $5^{\prime}$ & CACAGTCAAACATGAGCTTGGTGTATCGA & $3^{\prime}$ \\
NF-Y & $5^{\prime}$ & CTTGGTGTCGACCTGTITTGCCATAT & $3^{\prime}$
\end{tabular}

Electrophoretic mobility shift assays

\begin{tabular}{llll}
\hline Putative TFs binding motif in UGT1A1 proximal promoter & & \\
OCT1 & $5^{\prime}$ & GTGGAAATACTAATTAATGGA & $3^{\prime}$ \\
CDX2 & $5^{\prime}$ & GACTGACAGCTTTTATAGTCA & $3^{\prime}$ \\
CREB/USF/SREBP1 & $5^{\prime}$ & TITTATAGTCACGTGACACAGTC & $3^{\prime}$ \\
HNF1 & $5^{\prime}$ & CACAGTCAAACATTAACTTG & $3^{\prime}$ \\
NF-Y & $5^{\prime}$ & CTTGTGTATCGATTGGTITTGCAT & $3^{\prime}$ \\
PBX & $5^{\prime}$ & TGTATCGATTGTTITGCCATATAT
\end{tabular}

Consensus oligonucleotide probes used in competition assays ${ }^{2}$

$\begin{array}{llll}\text { OCT1 consensus oligo } & 5^{\prime} & \text { TGTCGAATGCAAATCACTAGAA } & 3^{\prime} \\ \text { CDX2 consensus oligo } & 5^{\prime} & \text { GTGCAATAAAACTTATGAGTA } & 3^{\prime} \\ \text { USF consensus oligo } & 5^{\prime} & \text { CACCCGGTCACGTGGCCTACACC } & 3^{\prime} \\ \text { HNF1 consensus oligo } & 5^{\prime} & \text { CCAGGTTAATGATTAACCCA } & 3^{\prime} \\ \text { NF-Y consensus oligo } & 5^{\prime} & \text { AGACCGTACGTGATTGGTTATCTCTT } & 3^{\prime} \\ \text { PBX consensus oligo } & 5^{\prime} & \text { CGATTGATTGATGCACTAATTGCAG } & 3^{\prime}\end{array}$

Oligonucleotide probes of the UGT1A1 promoter with CpG sites ${ }^{\mathrm{b}}$

$\begin{array}{llll}\text { CpG-4/USF } & 5^{\prime} & \text { AGCTTITTATAGTCACGTGACACAGTCAAACAT } & 3^{\prime} \\ \text { CpG-4/USF-HNF1 } & 5^{\prime} & \text { TCACGTGACACAGTCAAACATTAACTTGGT } & 3^{\prime}\end{array}$

Reverse transcription (RT)-PCR

Target gene
HNF-1 $\alpha$ Forward
HNF-1 $\alpha$ Reverse
USF-1 Forward
USF-1 Reverse
USF-2 Forward
USF-2 Reverse
GAPDH Forward
GAPDH Reverse
a TF recognition core sequence is underlined.
b UGT1A1 promoter CpG sites are underlined.

human UGT1A1 gene promoter (pUGT1A1-540/-1). These constructions were introduced into the pGL3luciferase reporter plasmid and transfected in UGT1A1expressing HT29 cells. UGT1A1 proximal promoter activity was significantly attenuated by disruption of HRE and URE (Figure 3). In contrast, mutations in the NF-Y and OCT1 binding motifs had no effect on transcriptional activity. The result for OCT1 is in accordance with previous EMSA experiments. Accordingly, these results established that HRE and URE would play a role in positive regulation of the UGT1A1 gene expression.

\section{CpG methylation at the USF response element inhibits} the formation of specific DNA-protein complex

As described above, the CpG-4 is part of the USF recognition core sequence. Therefore, we may expect that cytosine methylation at this site would hinder specific TF interaction. On the other hand, the HRE is found between CPG-3 and -4 dinucleotides and should 

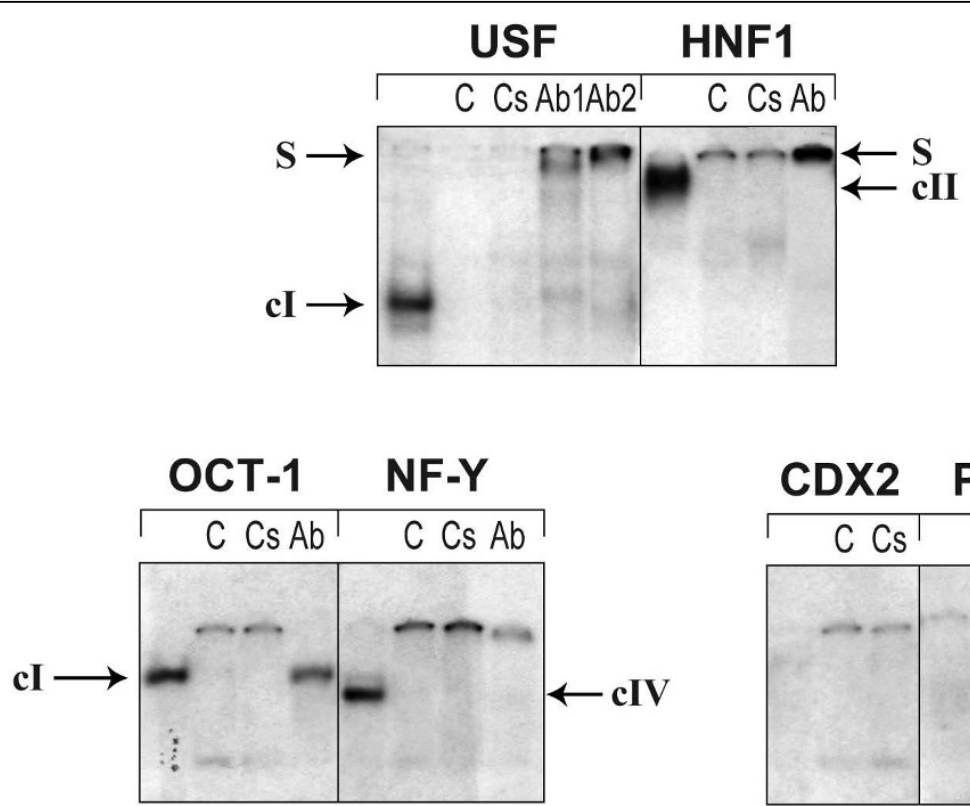

CDX2 PBX

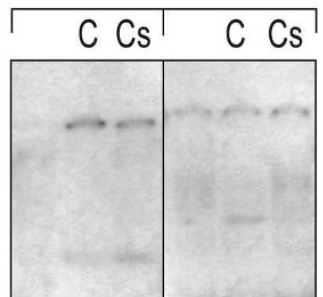

Figure 2 Interaction of transcription factors with the UGT1A1 promoter using protein nuclear extracts of UGT1A1-expressing HT29 colon cancer cells. EMSAs were performed with 32P-end-labeled probes. Nuclear protein extracts $(5 \mu \mathrm{g})$ from HT29 cells were pre-incubated in the presence of either no competitor or 100-fold molar excess of cold competitor oligonucleotides (C) or consensus sequence (Cs). For supershift assays, $2 \mu \mathrm{g}$ of the indicated antibody (Ab) were added directly after the addition of the labeled probe. For USF assays, Ab1 and Ab2 are directed against USF1 and USF2, respectively.

intuitively not be affected by CpG-related DNA methylation. To investigate this, we firstly performed EMSAs using a double-stranded oligonucleotide probe including the URE. The oligonucleotide has been either methylated or not at the CpG-4 dinucleotide (Figure 4). Incubation of in vitro translated USF1 proteins with either methylated or unmethylated 32P-labeled probe resulted in the formation of specific DNA-protein complexes (identified as complex I). This indicates that 5-methylcytosine did not totally prevent the USF1 protein binding. However, the protein binding to unmethylated probe is less competed by 100 -fold excess of methylated oligonucleotide than the unmethylated one, whereas binding to methylated probe is equally competed by either methylated or unmethylated cold oligonucleotide. It suggests that USF1 may interact with methylated DNA but have

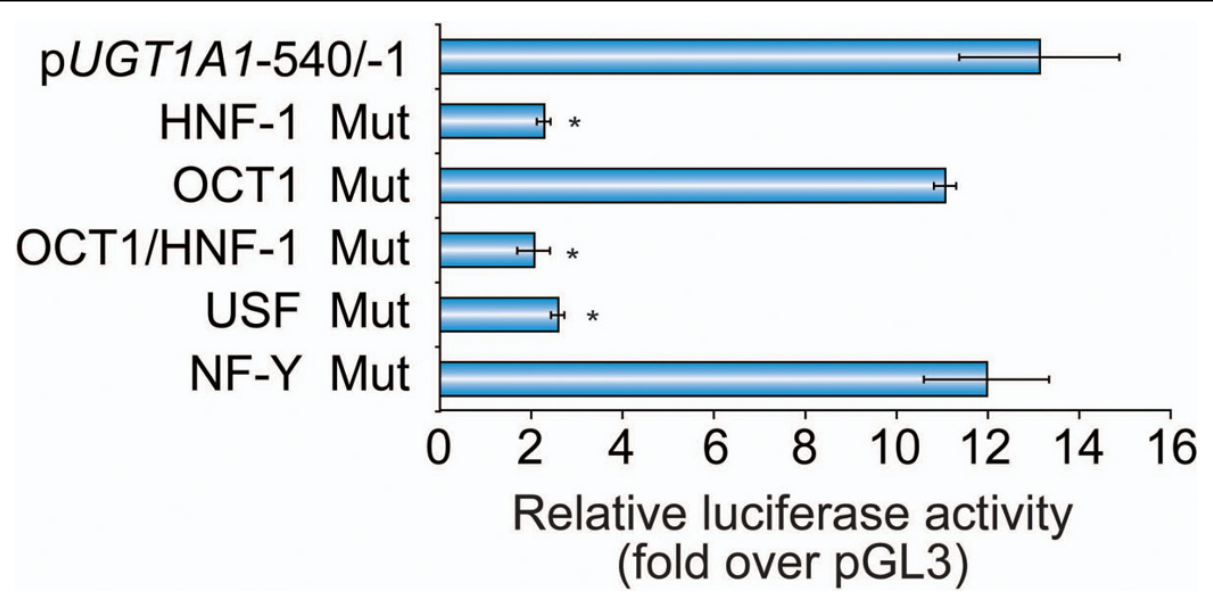

Figure 3 Disruption of HNF1-alpha and USF recognition sequences decreases UGT1A1 basal expression in HT29 cells. Mutational analysis of the putative HNF1, OCT1, USF and NF-Y binding sites in the UGT1A1 proximal promoter. Relative luciferase activity is expressed as a fold induction over the promoterless $\mathrm{pGL3}$-basic vector (set to value $=1$ ). Columns, mean of triplicates of three independent experiments; bars, $\mathrm{SD} ;{ }^{*}, \mathrm{P}<0.05$ 
higher affinity for its unmethylated binding motif. The incubation of USF1 protein with either anti-USF1 or anti-USF2 antibody well demonstrated that USF1 specifically bind this UGT1A1 promoter sequence. The absence of supershifted complex with anti-USF2 antibody denotes that antibody-induced supershifted complex is not caused by a non-specific interaction with the antibody.

In a second EMSA experiment, we examined the interaction between USF1/2 and HNF1-alpha (from HT29 nuclear protein extracts) with $U G T 1 A 1$ promoter sequence including both TF binding sites. We used solely unmethylated oligonucleotide as probe, but either unmethylated or methylated oligonucleotide as cold competitor (Figure 5). We observed the formation of two specific and one unspecific DNA-protein complexes. By specific competition with HRE or URE-containing oligonucleotide, we determined that DNA-protein complex I and II are formed by HNF1-alpha and USF1/2, respectively. We noted that solely the specific complex I is equally competed by excess of both methylated and unmethylated cold competitor. In contrast the complex II, formed by USF1/2, is more competed by molar excess of unmethylated cold competitor. The unspecific DNA-protein complex is not competed by either competitor. The positive correlation between the unspecific complex intensity and the increase amount of competitor indicates a rise in probe availability for nonspecific DNA-binding proteins. In summary, this experiment further demonstrated that $\mathrm{CpG}$ methylation impairs DNA-binding for USF1/2 but not for HNF1-alpha, likely because its recognition site remains unaffected by $\mathrm{CpG}$ methylation in our experiment context.

\section{Upregulation of HNF1A gene expression is observed following treatment with the 5-Aza-dC demethylating agent in UGT1A1-negative cells}

We presented that $\mathrm{CpG}$ methylation might affect UGT1A1 gene expression through alteration of cis-acting elements. However, evidence supports that DNA methylation-induced gene silencing is also caused by inhibition of trans-acting factor gene expression. We previously demonstrated that the UGT1A1-negative cell line HCT116 is able to express UGT1A1 following 5aza-dC treatment [14]. We showed that such a gene induction is due, at least in part, by the demethylation of UGT1A1 promoter. Considering the importance of HNF1-alpha and USF1/2 in UGT1A1 gene expression and also that HCT116 cell line is known to be HNF1negative, we sought to determine whether the USF1 and USF2 gene expression is influenced by the cell methylation status and whether $H N F 1 A$ gene expression is restored in 5-aza-dC-treated HCT116 hypermethylated cells. As expected, the presence of $H N F 1 A$ mRNA was undetectable by reverse PCR in untreated HCT116 cells. However, the 5-Aza-dC treatment induced the HNF1A gene expression (Figure 6). These data support that HNF1A is also modulated in these cells by methylation,

\section{Probe

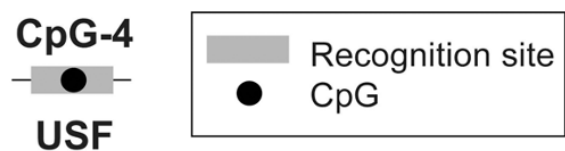

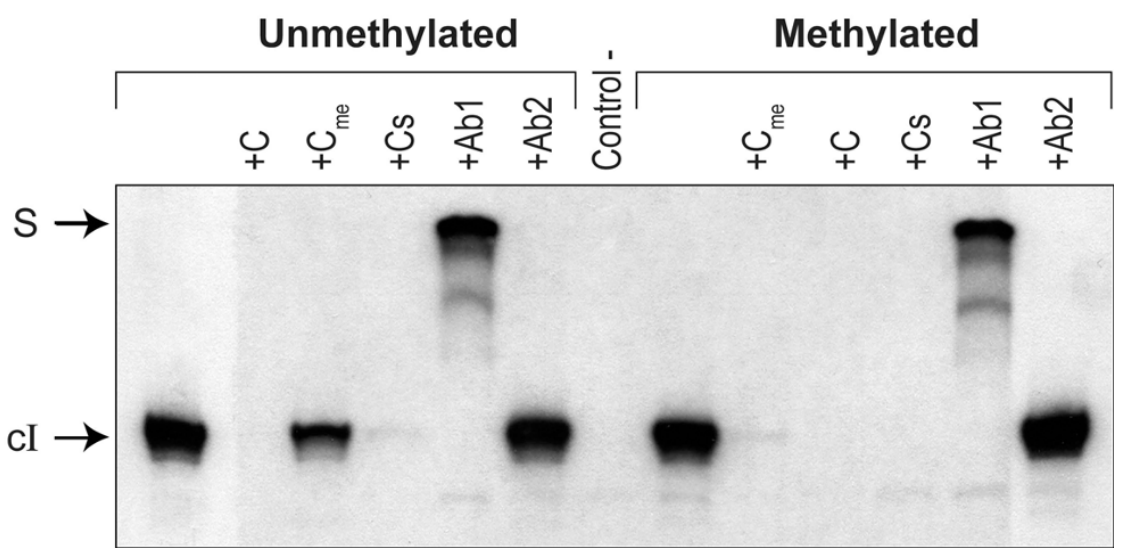

Figure 4 Incubation with in vitro translated USF1 protein demonstrates that methylation of CpG-4 impedes USF1 binding. EMSAs were performed with 32P-end-labeled probes. In vitro translated USF1 proteins were pre-incubated in the presence of either no competitor or 100fold molar excess of cold competitor oligonucleotides (C) or consensus sequence (Cs). For supershift assay, $2 \mu \mathrm{g}$ of the indicated antibody (Ab) were added directly after the addition of the labeled probe. Ab1 and Ab2 are directed against USF1 and USF2, respectively. In methylated probes, $\mathrm{dC}$ nucleotide is substituted by an internal methyl deoxyCytidine in CpG-4 dinucleotide. 


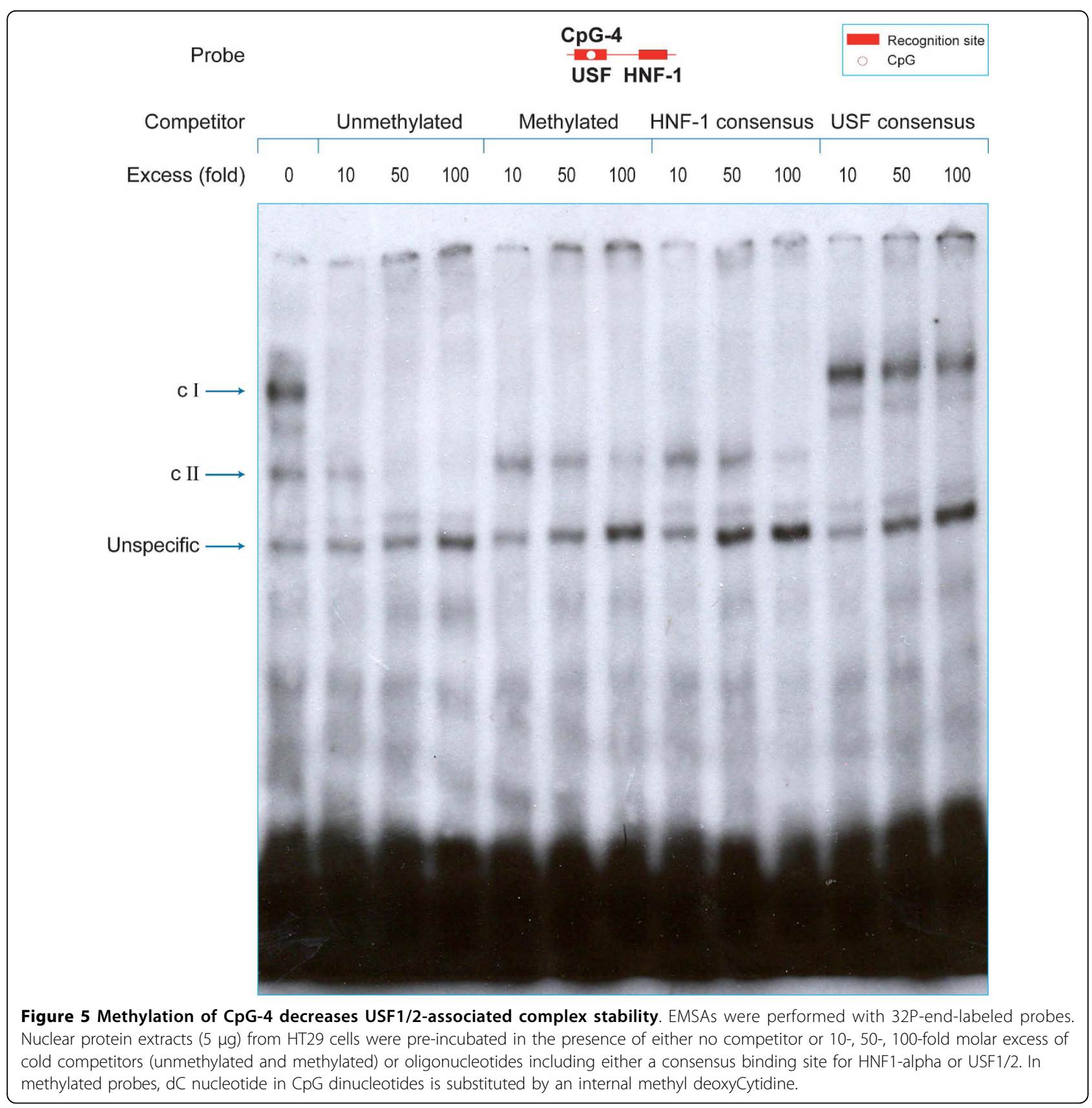

as observed for $U G T 1 A 1$. In fact, three regions in $H N F 1 A-5 \mathrm{~kb}$ promoter were predicted as CpG islands by the CpGPlot program (Emboss) (data not shown). On the other hand, we did not get any observable variation in both USF1 and USF2 gene expression following treatment with 5 -aza-dC in both cell lines.

\section{Discussion}

In this report, we predicted several putative TF binding sites in UGT1A1 proximal promoter using a bioinformatic tool and demonstrated by EMSA that HNF1- alpha, USF1/2, and NF-Y would bind to UGT1A1 proximal promoter. The influence of these TFs upon UGT1A1 transcriptional activity was then demonstrated by transient transfection in colon adenocarcinoma cell line HT29, and solely HNF1-alpha and USF1/2 have been shown to have significant impact.

Mutations in the HNF1-alpha motif resulted in a substantial reduction of $U G T 1 A 1$ promoter activity in HT29 cells. This HRE located in the human UGT1A1 promoter consists of a very well conserved half-site and a more divergent one with respect to the consensus 


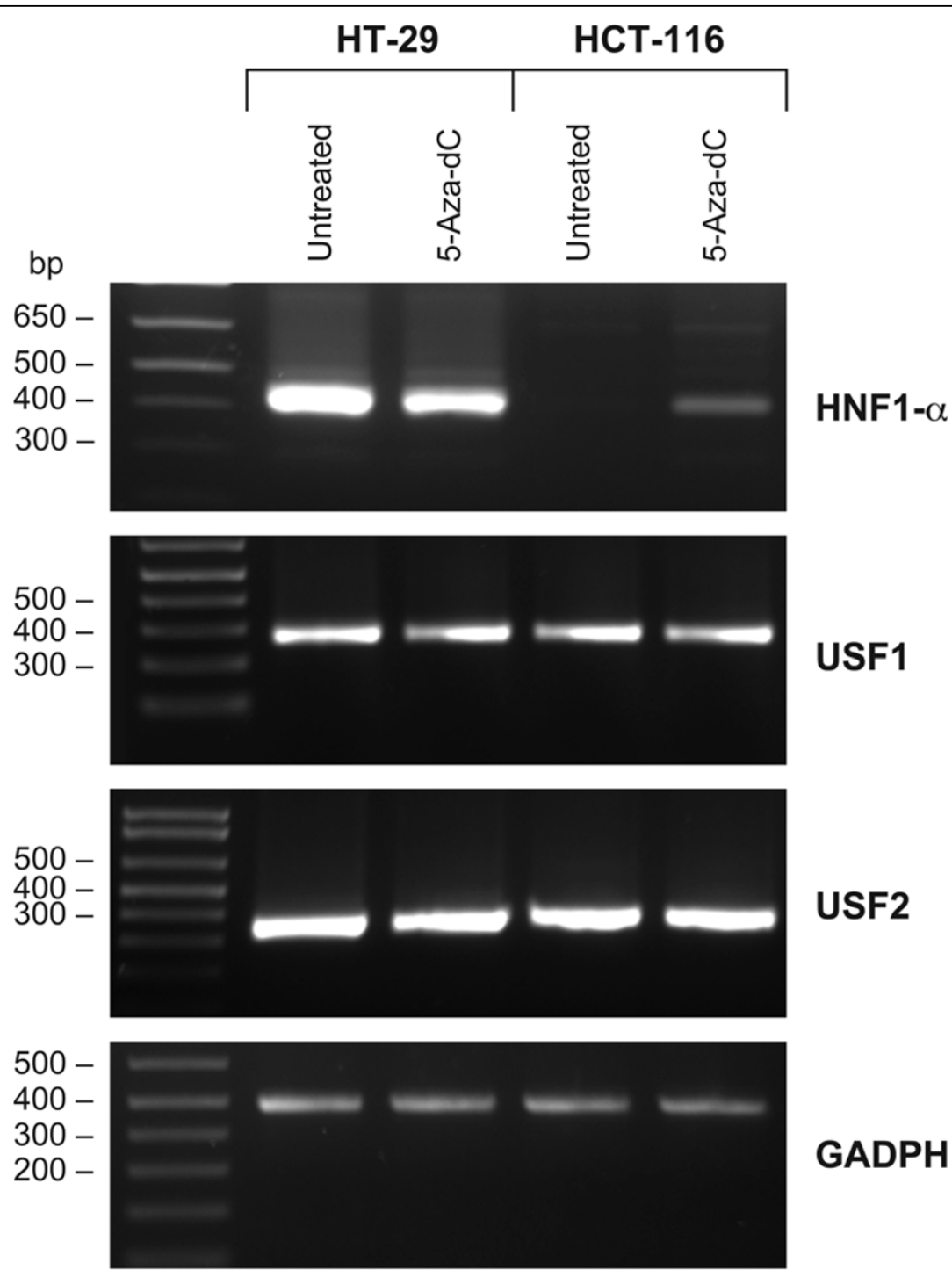

Figure 6 Upregulation of HNF1A expression is observed following treatment with the 5-Aza-dC demethylating agent in UGT1A1negative HCT116 colon cancer cells. Rescue of HNF1A gene expression by 5-Aza-dC treatment of colon carcinoma cell lines. Total RNA from HT29 and HCT116 cells were randomly converted to CDNA and specific amplification for USF1, USF2, and HNF1 mRNAs were carried out. Expression of USF1 and USF2 mRNAs are not influenced by 5-Aza-dC treatment. GAPDH gene is used as internal control. Untreated; cells not exposed to 5-Aza-dC.

sequence, which is very similar to the one from mouse UGT1A1 promoter and rat albumin promoter [26,27]. Consistent with previous studies in mice, HNF1-alpha proteins failed to bind (data not shown) and trans-activate the human UGT1A1 promoter when the conserved half-site is altered (Table 1). Besides, our data indicate that the one half of the HRE palindromic sequence is sufficient for its recognition of the UGT1A1 promoter, and that HNF1-alpha is critical for UGT1A1 expression.

HNF1-alpha is well-known to be involved in regulation of several UGTs, including human UGT2B7, UGT2B17, UGT1A1, UGT1A3, UGT1A4, UGT1A8,
UGT1A9, UGT1A10 and rat UGT1A7 [20,21,26,28-30]. Although the role of HNF1-alpha in the regulation of UGT1A1 has already been studied [26], the data were limited to transient transfections of the $-617 /+15$ UGT1A1 promoter and its HNF1-deleted construct into UGT1A1-negative HEK293 kidney cells. In here, we emphasized the importance of HNF1-alpha in the regulation of UGT1A1, and in contrast to previous observations, data were demonstrated in cells with a known glucuronidation capacity.

As observed for HNF1-alpha, mutations in URE also resulted in a drastic reduction of the promoter activity 
in HT29 cells, supporting for the first time, a role for this TF in the regulation of UGT1A1 promoter. Upstream stimulatory factors, USF1 and 2 are late TFs able to interact as homo- and/or heterodimers on $\mathrm{E}$ boxes of CACGTG sequence [31-34]. USFs are ubiquitously expressed proteins that have been described as positive or negative regulators of numerous genes, including cyclin-cdk encoding genes, tumour suppressor genes, and growth factor networks $[35,36]$. To our knowledge, no interaction of USF1 or USF2 with phase II enzymes such as the UGT family members has been documented thus far.

While EMSA indicated that NF-Y might also bind UGT1A1 promoter, mutations in its binding motif did not significantly reduce the luciferase activity compared with the wild-type construct in HT29 cells, suggesting that basal promoter activity does not require direct interaction of this TF. Although informative, promoterreporter constructs inadequately mimic the chromosomal context. It is now appreciated that chromatin-associated factors are various key determinants for specific gene expression [37]. Accordingly, we may not rule out that NF-Y would contribute to UGT1A1 gene expression in native cells.

The observation that URE includes a CpG dinucleotide contact point, which is critical for recognition by the USF proteins, prompted us to hypothesize that a USF E-box element that contained 5-methylcytosine in the CACGTG core might affect the binding for USF1/2. EMSA using unmethylated probe resulted in the formation of an USF-UGT1A1 complex. When methylated, URE-containing oligonucleotide competed poorly for USF1/2 binding, showing that specific methylation of CpG-4 dinucleotide decrease the affinity for USF1/2. It was previously shown that methylation at the $\mathrm{CpG}$ site, centrally located in the E-box motif (CACpGTG), strongly inhibits formation of DNA-protein complex $[38,39]$ and negatively regulates gene expression. Single nucleotide polymorphisms, within the E-box core motif, also modulate gene regulation. Notably, a single G/C base transition within the USF E-box consensus of the thymidylate synthase gene, implicated in folate metabolism, prevents USF proteins from binding to their cognate sequence [40].

As we observed previously for UGT1A1 [14], data indicate that DNA methylation is one mechanism likely involved in the down-regulation of HNF1A gene expression in colon cells. DNA methyltransferase inhibitor treatment of UGT1A1-negative HCT116 colon cells restored HNF1A gene expression. 5-aza-dC-induced gene reactivation has two distinct requirements: 1) the reversal of promoter DNA hypermethylation, and 2) the presence of transcriptional activators competent for activation of the target promoter. Considering that HNF1- alpha is essential for $U G T 1 A 1$ gene expression, the methylation of $H N F 1 A$ gene promoter represents a second level of DNA methylation-mediated regulation, which highlights the complexity of epigenetic gene regulation. The modulation of HNF1A expression might also have impact on the regulation of other genes, notably on additional phase II enzymes including other UGTs [20,21,26,28-30], glutathione transferase [41], and sulfotransferase [42].

Interestingly, the UGT1A1-associated HRE, which is free of $\mathrm{CpG}$ dinucleotide, is located between CpG-3 and -4 , and we demonstrated that methylation of proximal CpG dinucleotides is not sufficient to significantly alter HNF1-alpha binding in vitro. However, we may not rule out the importance of DNA methylation in the binding of HNF1-alpha in vivo, because such a DNA modification induces a repressive chromatin structure, and might restrain the accessibility of HNF1-alpha to its recognition sequence in UGT1A1 promoter. However, we suggest that $U G T 1 A 1$ proximal promoter methylation may directly affect transcriptional activity by suppressing the interaction of USF1/2 with its cognate sequence.

Taken together, our results reveal that both HNF1alpha and USF $1 / 2$ could play an important role in activating the transcription from UGT1A1 promoter. The interplay between HNF1-alpha and USF1/2 has been previously shown to be implicated in the liver-specific expression of the pyruvate kinase gene, in the regulation of three human class I alcohol dehydrogenase genes and in the constitutive expression of CYP1A2 [43-45]. Considering that UGT1A1-mediated glucuronidation is the primary route of irinotecan inactivation, it was suggested that the level of UGT1A1 expression might contribute to the differential chemosensitivity of colon tumors [46-48]. In a previous report, we showed that methylation of UGT1A1 promoter may conduct to reduction of gene expression level, leading to a lower UGT1A1 glucuronidation activity. Accordingly, positive UGT1A1 methylation in tumors, and subsequent repression of UGT1A1-associated metabolic pathways would be involved in retention of active SN-38 within colon cancer cells. This could lead to higher sensitivity to irinotecan. In contrast, the presence of high levels of UGT activity and expression was identified as a characteristic associated with a resistance phenotype to $\mathrm{SN}-38$ in colon cancer cells, as supported by a previous report [9].

\section{Conclusions}

This study reveals that basal UGT1A1 expression in colon cells is positively regulated by sequence-specific binding of HNF1-alpha and USF1/2, and negatively regulated by DNA methylation of CpG-4 located in the proximal UGT1A1 promoter. This suggests that CpG-4 methylation status might be a relevant indicator of 
UGT1A1 proximal promoter methylation and by consequence a potential epigenetic marker of UGT1A1 gene expression. Besides, epigenetic regulation of HNF1A gene could also play an important role in regulating additional cellular drug metabolism and transporter pathways. Altogether, the epigenetic regulation of HNF1A and UGT1A1 genes may contribute to determine local inactivation of drugs, such as the anticancer agent $\mathrm{SN}-38$ by glucuronidation and define tumoral response to irinotecan. Further studies are required to examine this hypothesis.

\section{Methods}

\section{Cell culture}

Colon cancer cells HT29 and HCT116 were obtained from American Type Culture Collection (Manassas, VA). Cells were growth in the medium recommended by American Type Culture Collection. HT29 and HCT116 cells were kept in McCoy's 5A medium with $1.0 \mathrm{mmol} / \mathrm{L}$ sodium pyruvate (Sigma, Oakville, Ontario, Canada) added with $100 \mathrm{IU} / \mathrm{mL}$ penicillin, $50 \mu \mathrm{g} / \mathrm{mL}$ streptomycin, and $10 \%$ fetal bovine serum. Cells were incubated at $37^{\circ} \mathrm{C}$ in a humidified incubator with $5 \%$ $\mathrm{CO}_{2}$.

\section{Transient transfection}

The preparation of UGT1A1 promoter-luciferase reporter constructs has been previously described [14]. For transient transfections, cells were plated into 24-well microplates at approximately 80 percent of confluence $(150,000$ Cells/well) in growth medium and transfected using Lipofectamine 2000 (Invitrogen, Carlsbad, CA) according to the manufacturer's instructions. UGT1A1 promoter-luciferase reporter constructs were used at $750 \mathrm{ng}$ of plasmid per well and co-transfected with $5 \mathrm{\eta g}$ of Renilla luciferase plasmid. Cells were harvested 48 hours after transfection and assayed for promoter activity using the Dual-Luciferase Reporter Assay System. Luciferase activity was measured by using $40 \mu \mathrm{L}$ of cell lysate in a 96-well plate on an LB96V microplate luminometer.

\section{Site-directed mutagenesis}

Site-directed mutants were constructed with the The QuickChange mutagenesis kit (Stratagene) and the mutated oligonucleotides (Table 1). Mutations were confirmed by DNA sequencing before subcloning into the pGL3-Basic vector.

\section{Expression analysis by reverse transcription (RT)-PCR}

Treatments with 5-Aza-dC were done as described previously [14] and RNA from HCT116 cancer cell line was extracted with Tri-Reagent (Molecular Research Center, Inc., Cincinnati, OH), as described in the manufacturer's protocol. RNA $(1 \mu \mathrm{g})$ was converted to cDNA with SuperScript II RNase H-negative (Invitrogen, Burlington, Ontario, Canada) using the manufacturer's protocol in a 20 ul reaction volume. The amplification reactions were carried out in a $25 \mathrm{ul} \mathrm{reac-}$ tion volume including $1 \mathrm{ul}$ of cDNA reaction, $10 \mathrm{pmol}$ of each primer (listed in table 1), 200 pmol of dNTP, 1× Taq PCR buffer, 5\% Acetamide, 0,5 unit of Taq DNA polymerase. 35 amplification cycles were peformed as follow: $20 \mathrm{sec}$ at $95^{\circ} \mathrm{C}, 20 \mathrm{sec}$ at $61^{\circ} \mathrm{C}$, and $30 \mathrm{sec}$ at $72^{\circ}$ C. A $10 \mu \mathrm{L}$ aliquot of each reaction mixture was electrophoresed on a $1 \%$ agarose gel containing ethidium bromide. The GAPDH gene was amplified as internal control.

\section{Preparation of nuclear extracts and in vitro production of} USF protein

Nuclear extracts were prepared from trypsinized cells, centrifuged for $5 \mathrm{~min}$ at $800 \times \mathrm{g}$ and then resuspended in $5 \mathrm{ml}$ of $\mathrm{HB}$ buffer ( $15 \mathrm{mM}$ Tris- $\mathrm{HCl}$ (pH 8.0), 15 $\mathrm{mM} \mathrm{NaCl}, 60 \mathrm{mM} \mathrm{KCl}, 0,5 \mathrm{mM}$ EDTA), centrifuged at $800 \times \mathrm{g}$ for $5 \mathrm{~min}$, resuspended in $100 \mu \mathrm{l}$ of HB buffer supplemented with $0.05 \%$ Triton X-100 (Sigma), and centrifuged for $10 \mathrm{~min}$ at $1,000 \times \mathrm{g}$, and the supernatant was discarded. The pellet was washed with $5 \mathrm{ml}$ of $\mathrm{HB}$ buffer containing $0.05 \%$ Triton X-100 and $5 \mathrm{ml}$ of $\mathrm{HB}$ buffer. Nuclei were incubated at $4^{\circ} \mathrm{C}$ for $30 \mathrm{~min}$ in $50 \mu \mathrm{l}$ of $\mathrm{HB}$ buffer containing $360 \mathrm{mM} \mathrm{KCl}$ and centrifuged for $5 \mathrm{~min}$ at $10,000 \times \mathrm{g}$, and the supernatant corresponding to the nuclear extract was collected. The concentration of protein in the extracts was determined using the Bradford method according to the manufacturer's recommendations. Human USF1 cDNA clone was kindly provided by Dr. Roger G. Roeder and described previously [49]. USF1 protein was synthesized in vitro using the TNT Quick Coupled Transcription/ Translation System (Promega, Madison, Wisconsin, USA).

\section{Electrophoretic mobility shift assay (EMSA)}

Protein-DNA interactions were carried out in a $20 \mathrm{ul}$ reaction mixture including either $5 \mu \mathrm{g}$ crude nuclear protein extract in (figure 2 and 5) or in vitro synthesized USF proteins (in figure 4), $50 \mathrm{mM}$ HEPES (pH 7.8), 300 $\mathrm{mM} \mathrm{KCl}, 1 \%$ Igepal, 30\% glycerol, $1 \mathrm{mM}$ DTT, $0.01 \mu \mathrm{g}$ of poly (dI-dC), $0.05 \mu \mathrm{g}$ of ssDNA, and $20000 \mathrm{CPM}$ of 32P-radiolabeled oligonucleotide. After incubation for 20 minutes at room temperature, the protein-DNA complexes were resolved onto $6 \%$ non-denaturing polyacrylamide gel electrophoresis at $4^{\circ} \mathrm{C}$ (when using nuclear extracts) and at room temperature (when using in vitro translated USF proteins). For competition experiments, unlabeled oligonucleotides were added in the reaction mixture at a molar excess of 100-fold (Figures 2 and 4), 
or 10 to 100 -fold (figure 5). The oligonucleotides including consensus recognition sequence for transcription factors (Table 1) are derived from Transcruz gel shift oligonucleotides (SantaCruz Biotechnology, CA), except for CDX2[50] and HNF1[51]. For supershift assays, $2 \mu \mathrm{g}$ of a monoclonal (Biogenex, San Ramon, California, USA) antibody to human CDX2 or polyclonal antibody to HNF1-alpha (C-19), NF-Y (CBF-B, C-18) OCT1 (C21), USF1 (C-20) and USF2 (C-20) (Santa Cruz Biotechnology, Inc., Santa Cruz, California, USA) were added directly after the addition of labeled probe, with the exception of pre-incubation experiments where antibodies were pre-incubated for $30 \mathrm{~min}$ prior to probe addition.

\section{Acknowledgements}

We gratefully thank Dr. Roger G. Roeder for providing human USF1 cDNA. This work was supported by the Canadian Institutes of Health Research (CIHR MOP-42392) program. A-S.B. is supported by CIHR Frederick Banting and Charles Best studentship award. J.T is recipient of a F.R.S.Q ('Fonds de la Recherche en Santé du Québec') studentship award. C.G. holds a Canada Research Chair in Pharmacogenomics.

\section{Author details}

${ }^{1}$ Pharmacogenomics Laboratory, Centre Hospitalier Universitaire de Québec (CHUQ), 2705 Laurier, Quebec, G1V 4G2, Canada. ${ }^{2}$ Faculty of Pharmacy, Laval University, Quebec, G1V 0A6, Canada.

\section{Authors' contributions}

ASB: acquisition of data; analysis and interpretation of data; drafting of the manuscript. JT: acquisition of data; analysis and interpretation of data. $\mathrm{MH}$ : analysis and interpretation of data; critical revision of the manuscript for important intellectual content. CG: study concept and design; study supervision, critical revision of the manuscript for important intellectual content; obtained funding. All authors have read and approved the final version of the manuscript.

Received: 23 June 2009

Accepted: 22 January 2010 Published: 22 January 2010

\section{References}

1. Saltz LB, Cox JV, Blanke C, Rosen LS, Fehrenbacher L, Moore MJ, Maroun JA, Ackland SP, Locker PK, Pirotta N, et al: Irinotecan plus fluorouracil and leucovorin for metastatic colorectal cancer. Irinotecan Study Group. N Engl J Med 2000, 343(13):905-914.

2. Douillard JY, Cunningham D, Roth $A D$, Navarro M, James RD, Karasek $P$, Jandik P, Iveson T, Carmichael J, Alakl M, et al: Irinotecan combined with fluorouracil compared with fluorouracil alone as first-line treatment for metastatic colorectal cancer: a multicentre randomised trial. Lancet 2000, 355(9209):1041-1047.

3. Rougier P, Van Cutsem E, Bajetta E, Niederle N, Possinger K, Labianca R, Navarro M, Morant R, Bleiberg H, Wils J, et al: Randomised trial of irinotecan versus fluorouracil by continuous infusion after fluorouracil failure in patients with metastatic colorectal cancer. Lancet 1998 352(9138):1407-1412.

4. Kawato $Y$, Aonuma M, Hirota $Y$, Kuga H, Sato K: Intracellular roles of SN-38, a metabolite of the camptothecin derivative CPT-11, in the antitumor effect of CPT-11. Cancer Res 1991, 51(16):4187-4191.

5. Haaz MC, Rivory L, Riche C, Vernillet L, Robert J: Metabolism of irinotecan (CPT-11) by human hepatic microsomes: participation of cytochrome $\mathrm{P}$ $4503 \mathrm{~A}$ and drug interactions. Cancer Res 1998, 58(3):468-472.

6. Gagne JF, Montminy V, Belanger P, Journault K, Gaucher G, Guillemette C: Common human UGT1A polymorphisms and the altered metabolism of irinotecan active metabolite 7-ethyl-10-hydroxycamptothecin (SN-38). Mol Pharmacol 2002, 62(3):608-617.
7. Iyer L, Hall D, Das S, Mortell MA, Ramirez J, Kim S, Di Rienzo A, Ratain MJ: Phenotype-genotype correlation of in vitro SN-38 (active metabolite of irinotecan) and bilirubin glucuronidation in human liver tissue with UGT1A1 promoter polymorphism. Clin Pharmacol Ther 1999, 65(5):576-582.

8. Hanioka N, Ozawa S, Jinno H, Ando M, Saito Y, Sawada J: Human liver UDP-glucuronosyltransferase isoforms involved in the glucuronidation of 7-ethyl-10-hydroxycamptothecin. Xenobiotica 2001, 31(10):687-699.

9. Cummings J, Boyd G, Ethell BT, Macpherson JS, Burchell B, Smyth JF, Jodrell DI: Enhanced clearance of topoisomerase I inhibitors from human colon cancer cells by glucuronidation. Biochem Pharmacol 2002, 63(4):607-613.

10. Issa JP: CpG island methylator phenotype in cancer. Nat Rev Cancer 2004, 4(12):988-993.

11. Laird PW: Cancer epigenetics. Hum Mol Genet 2005, 14(Spec No 1):R65-76.

12. Al-Romaih K, Somers GR, Bayani J, Hughes S, Prasad M, Cutz JC, Xue H, Zielenska M, Wang $Y$, Squire JA: Modulation by decitabine of gene expression and growth of osteosarcoma U2OS cells in vitro and in xenografts: Identification of apoptotic genes as targets for demethylation. Cancer Cell Int 2007, 7(14).

13. Toyota M, Ahuja N, Ohe-Toyota M, Herman JG, Baylin SB, Issa JP: CpG island methylator phenotype in colorectal cancer. Proc Natl Acad Sci USA 1999, 96(15):8681-8686.

14. Gagnon JF, Bernard O, Villeneuve L, Tetu B, Guillemette C: Irinotecan inactivation is modulated by epigenetic silencing of UGT1A1 in colon cancer. Clin Cancer Res 2006, 12(6):1850-1858.

15. Clark SJ, Harrison J, Molloy PL: Sp1 binding is inhibited by $(\mathrm{m}) \mathrm{Cp}(\mathrm{m}) \mathrm{CpG}$ methylation. Gene 1997, 195(1):67-71.

16. Gaston K, Fried M: CpG methylation has differential effects on the binding of $Y Y 1$ and ETS proteins to the bi-directional promoter of the Surf-1 and Surf-2 genes. Nucleic Acids Res 1995, 23(6):901-909.

17. Umezawa A, Yamamoto H, Rhodes K, Klemsz MJ, Maki RA, Oshima RG: Methylation of an ETS site in the intron enhancer of the keratin 18 gene participates in tissue-specific repression. Mol Cell Biol 1997, 17(9):4885-4894

18. Karpf AR, Jones DA: Reactivating the expression of methylation silenced genes in human cancer. Oncogene 2002, 21(35):5496-5503.

19. Gardner-Stephen DA, Gregory PA, Mackenzie PI: Identification and characterization of functional hepatocyte nuclear factor 1-binding sites in UDP-glucuronosyltransferase genes. Methods Enzymol 2005, 400:22-46.

20. Gardner-Stephen DA, Mackenzie PI: Isolation of the UDPglucuronosyltransferase $1 \mathrm{~A} 3$ and $1 \mathrm{~A} 4$ proximal promoters and characterization of their dependence on the transcription factor hepatocyte nuclear factor 1alpha. Drug Metab Dispos 2007, 35(1):116-120.

21. Gregory PA, Lewinsky RH, Gardner-Stephen DA, Mackenzie PI: Coordinate regulation of the human UDP-glucuronosyltransferase $1 \mathrm{~A} 8,1 \mathrm{~A} 9$, and $1 \mathrm{~A} 10$ genes by hepatocyte nuclear factor 1 alpha and the caudal-related homeodomain protein 2. Mol Pharmacol 2004, 65(4):953-963.

22. Gardner-Stephen DA, Mackenzie PI: Hepatocyte nuclear factor1 transcription factors are essential for the UDP-glucuronosyltransferase 1A9 promoter response to hepatocyte nuclear factor 4alpha. Pharmacogenet Genomics 2007, 17(1):25-36.

23. Gardner-Stephen DA, Mackenzie PI: Liver-enriched transcription factors and their role in regulating UDP glucuronosyltransferase gene expression. Curr Drug Metab 2008, 9(5):439-452.

24. Gregory PA, Lewinsky RH, Gardner-Stephen DA, Mackenzie PI: Regulation of UDP glucuronosyltransferases in the gastrointestinal tract. Toxicol Appl Pharmacol 2004, 199(3):354-363.

25. Mackenzie PI, Gregory PA, Gardner-Stephen DA, Lewinsky RH, Jorgensen BR Nishiyama T, Xie W, Radominska-Pandya A: Regulation of UDP glucuronosyltransferase genes. Curr Drug Metab 2003, 4(3):249-257.

26. Bernard P, Goudonnet $H$, Artur Y, Desvergne B, Wahli W: Activation of the mouse TATA-less and human TATA-containing UDPglucuronosyltransferase 1A1 promoters by hepatocyte nuclear factor 1 . Mol Pharmacol 1999, 56(3):526-536.

27. Cereghini S: Liver-enriched transcription factors and hepatocyte differentiation. Faseb J 1996, 10(2):267-282.

28. Gregory PA, Hansen AJ, Mackenzie PI: Tissue specific differences in the regulation of the UDP glucuronosyltransferase $2 \mathrm{~B} 17$ gene promoter. Pharmacogenetics 2000, 10(9):809-820.

29. Ishii $Y$, Hansen AJ, Mackenzie Pl: Octamer transcription factor-1 enhances hepatic nuclear factor-1alpha-mediated activation of the human UDP 
glucuronosyltransferase 2B7 promoter. Mol Pharmacol 2000 57(5):940-947.

30. Metz RP, Auyeung DJ, Kessler FK, Ritter JK: Involvement of hepatocyte nuclear factor 1 in the regulation of the UDP-glucuronosyltransferase 1A7 (UGT1A7) gene in rat hepatocytes. Mol Pharmacol 2000, 58(2):319-327

31. Sawadogo M, Roeder RG: Interaction of a gene-specific transcription factor with the adenovirus major late promoter upstream of the TATA box region. Cell 1985, 43(1):165-175.

32. Chodosh LA, Carthew RW, Sharp PA: A single polypeptide possesses the binding and transcription activities of the adenovirus major late transcription factor. Mol Cell Biol 1986, 6(12):4723-4733.

33. Sawadogo M, Van Dyke MW, Gregor PD, Roeder RG: Multiple forms of the human gene-specific transcription factor USF. I. Complete purification and identification of USF from HeLa cell nuclei. J Biol Chem 1988, 263(24):11985-11993.

34. Sawadogo M: Multiple forms of the human gene-specific transcription factor USF. II. DNA binding properties and transcriptional activity of the purified HeLa USF. J Biol Chem 1988, 263(24):11994-12001.

35. Kingsley-Kallesen ML, Kelly D, Rizzino A: Transcriptional regulation of the transforming growth factor-beta2 promoter by CAMP-responsive element-binding protein (CREB) and activating transcription factor-1 (ATF-1) is modulated by protein kinases and the coactivators p300 and CREB-binding protein. J Biol Chem 1999, 274(48):34020-34028.

36. Szentirmay MN, Yang HX, Pawar SA, Vinson C, Sawadogo M: The IGF2 receptor is a USF2-specific target in nontumorigenic mammary epithelial cells but not in breast cancer cells. J Biol Chem 2003, 278(39):37231-37240.

37. Goldberg AD, Allis CD, Bernstein E: Epigenetics: a landscape takes shape. Cell 2007, 128(4):635-638.

38. Prendergast GC, Ziff EB: Methylation-sensitive sequence-specific DNA binding by the c-Myc basic region. Science 1991, 251(4990):186-189.

39. Watt F, Molloy PL: Cytosine methylation prevents binding to DNA of a HeLa cell transcription factor required for optimal expression of the adenovirus major late promoter. Genes Dev 1988, 2(9):1136-1143.

40. Mandola MV, Stoehlmacher J, Muller-Weeks S, Cesarone G, Yu MC, Lenz HJ, Ladner RD: A novel single nucleotide polymorphism within the $5^{\prime}$ tandem repeat polymorphism of the thymidylate synthase gene abolishes USF-1 binding and alters transcriptional activity. Cancer Res 2003, 63(11):2898-2904.

41. Paulson KE, Darnell JE Jr, Rushmore T, Pickett CB: Analysis of the upstream elements of the xenobiotic compound-inducible and positionally regulated glutathione S-transferase Ya gene. Mol Cell Biol 1990, 10(5):1841-1852

42. Song CS, Jung MH, Kim SC, Hassan T, Roy AK, Chatterjee B: Tissue-specific and androgen-repressible regulation of the rat dehydroepiandrosterone sulfotransferase gene promoter. J Biol Chem 1998, 273(34):21856-21866.

43. Narvaez MJ, Anderson GR, Pickwell GV, Quattrochi LC: Characterization of adjacent E-box and nuclear factor 1-like DNA binding sequence in the human CYP1A2 promoter. J Biochem Mol Toxicol 2005, 19(2):78-86.

44. Edenberg HJ, Brown CJ: Regulation of human alcohol dehydrogenase genes. Pharmacogenetics 1992, 2(5):185-196.

45. Vaulont S, Puzenat N, Levrat F, Cognet M, Kahn A, Raymondjean M: Proteins binding to the liver-specific pyruvate kinase gene promoter. A unique combination of known factors. J Mol Biol 1989, 209(2):205-219.

46. Strassburg CP, Nguyen N, Manns MP, Tukey RH: Polymorphic expression of the UDP-glucuronosyltransferase UGT1A gene locus in human gastric epithelium. Mol Pharmacol 1998, 54(4):647-654.

47. Lin YM, Furukawa Y, Tsunoda T, Yue CT, Yang KC, Nakamura Y: Molecular diagnosis of colorectal tumors by expression profiles of 50 genes expressed differentially in adenomas and carcinomas. Oncogene 2002, 21(26):4120-4128.

48. Yu J, Shannon WD, Watson MA, McLeod HL: Gene expression profiling of the irinotecan pathway in colorectal cancer. Clin Cancer Res 2005, 11(5):2053-2062.

49. Kirschbaum BJ, Pognonec $P$, Roeder RG: Definition of the transcriptional activation domain of recombinant 43-kilodalton USF. Mol Cell Biol 1992, 12(11):5094-5101.

50. Houde M, Laprise P, Jean D, Blais M, Asselin C, Rivard N: Intestinal epithelial cell differentiation involves activation of p38 mitogen- activated protein kinase that regulates the homeobox transcription factor CDX2. J Biol Chem 2001, 276(24):21885-21894.

51. Jain S, Li Y, Patil S, Kumar A: HNF-1alpha plays an important role in IL-6induced expression of the human angiotensinogen gene. Am J Physiol Cell Physiol 2007, 293(1):C401-410.

doi:10.1186/1471-2199-11-9

Cite this article as: Bélanger et al:: Regulation of UGT1A1 and HNF1 transcription factor gene expression by DNA methylation in colon cancer cells. BMC Molecular Biology 2010 11:9.

\section{Submit your next manuscript to BioMed Central and take full advantage of:}

- Convenient online submission

- Thorough peer review

- No space constraints or color figure charges

- Immediate publication on acceptance

- Inclusion in PubMed, CAS, Scopus and Google Scholar

- Research which is freely available for redistribution 